Gerión. Revista de Historia Antigua

ISSN: 0213-0181

http://dx.doi.org/10.5209/GERI.59926

\title{
La provincia de Arabia: ¿cambios en la sociedad petrense?
}

\author{
Carmen Blánquez ${ }^{1}$
}

Recibido: 21 de agosto de 2017 / Aceptado: 24 de noviembre de 2017

Resumen. Dado que no hay mucha información sobre la Petra romana, especialmente proveniente de textos escritos, la intención de este artículo es averiguar si los monumentos y edificios construidos o modificados en esta etapa, sumados a los resultados de recientes excavaciones arqueológicas llevadas a cabo en Petra -algunas de las cuales continúan en la actualidad- ofrecen la imagen de algunos cambios cuyo significado y alcance puedan comenzar a ser analizados.

Palabras clave: Petra romana; Arabia romana; arquitectura de Petra.

\section{[en] The Arabia Province: Changes in the Nabataean Society?}

\begin{abstract}
Since there is not much information on Roman Petra, especially from written texts, the aim of this article is whether the monuments and constructed or modified at this stage buildings, together with the results of recent archaeological excavations in Petra -some of which continue today- paint a picture of some changes, the meaning and scope can begin to be analyzed.
\end{abstract}

Key words: Roman Petra; Roman Arabia; Architecture of Petra.

Sumario: 1. Introducción. 2. El comienzo. 3. Las transformaciones y renovaciones. 3.1. La calle Columnada o calle Romana. 3.2. Las tiendas romanas de dos pisos. 3.3. La Puerta del témenos. 3.4. Las termas romano-bizantinas. 3.5. El Ninfeo. 4. Los cambios. 4.1. El Petra Garden Pool-Complex. 4.2. Gran Templo del Sur. 4.3. El Teatro Principal. 5. Las novedades. Los hallazgos más recientes. 5.1. "Pequeño Templo". 5.2. Témenos del templo nabateo de Qasr al-Bint. 6. La arquitectura funeraria. 6.1 La tumba del gobernador romano de Arabia Sextius Florentinus. 6.2. La Tumba 64. 6.3. LaTumba 550. 7. Conclusiones. 8. Referencias bibliográficas.

Cómo citar: Blánquez, C. (2017): La provincia de Arabia: ¿cambios en la sociedad petrense?, en Gerión 35(2), 597-617.

\footnotetext{
1 Universidad Complutense de Madrid.

E-mail: cblanque@ucm.es
} 


\section{Introducción}

Los estudios sobre la ciudad de Petra se centran, como es lógico, en la etapa nabatea pero también en el período bizantino, sobre todo después del descubrimiento del corpus de papiros del siglo VI d.C. ${ }^{2}$ que tanta información han proporcionado sobre el último siglo de ocupación de la ciudad. Sin embargo, los más de doscientos cincuenta años de fase romana (que coinciden con la existencia de la provincia de Arabia) se consideran como un puente que enlaza ambas épocas y que se cruza sin detenerse. Buena prueba de ello es que el libro Roman Arabia de G. Bowersock, publicado en 1983, sigue siendo continuamente citado y es el único estudio en profundidad sobre esta provincia romana. Muy probablemente, esto es debido a la falta de información sobre Arabia y los cambios producidos en lo que había sido durante siglos el floreciente reino nabateo. Términos como "oscuridad" o "enigma", se aplican comúnmente a la existencia de los nabateos bajo el dominio romano, incluso por parte de autores que investigan acerca de esta etapa y que han buscado entre las referencias literarias y epigráficas testimonios que permitan avanzar en su conocimiento, para acabar concluyendo que "for the present, the scraps and pieces about Nabatea after AD 106 represent a fairly confusing and choppy picture". ${ }^{3}$

Sin embargo, los modernos resultados obtenidos gracias a la arqueología en la Petra romana, sumados a la revisión de los ya obtenidos previamente, quizá puedan colaborar a despejar este panorama. Precisamente, la intención de este artículo es averiguar si el estudio de los monumentos -tanto rupestres como construidosde la ciudad, especialmente los hallados en recientes excavaciones arqueológicas llevadas a cabo -algunas de las cuales continúan en la actualidad- ofrecen una imagen de cambios, cuyo significado y alcance puedan comenzar a ser analizados.

Hemos escogido centrarnos en Petra por ser el lugar donde más abundantes han sido los trabajos arqueológicos, a pesar de que fue Bosra (en la actual Siria) la ciudad distinguida para ser la capital de la nueva provincia de Arabia. En cuanto al espacio cronológico examinado, no agota el de la presencia romana en la zona, sino que se detiene en el siglo IV, época bizantina en la que se crea la nueva provincia Palestina Tertia Salutaris. ${ }^{4}$ Precisando aún más, el tremendo terremoto que tuvo lugar en el año 363, que afectó gravemente a Petra, se utiliza aquí como límite ante quem.

\section{El comienzo}

La anexión de Nabatea fue muy tardía, pues tuvo lugar en el año 106 d.C. por orden del emperador Trajano. Abundando en la falta de información, esta noticia de la desaparición del reino nabateo y la creación de la provincia de Arabia aparece apenas mencionada en un único escritor relativamente contemporáneo, Dion Ca-

2 Los papiros se encontraron carbonizados durante la excavación efectuada en la conocida como Iglesia de los Mosaicos de Petra, dirigida por Z. Fiema y llevada a cabo en sucesivas campañas entre 1992 y 1994 (Fiema et alii 2001).

Graf 2007, 186.

4 Se duda de la fecha exacta de creación de dicha nueva provincia. El primer testimonio indudable es una referencia de Jerónimo quien, a fines del siglo IV, menciona la "provincia recientemente creada" (Hieron. Quaest. in Gen. 21.30). 
sio, quien cuenta que Cornelio Palma, legado romano de Siria "sometió la parte de Arabia alrededor de Petra y la convirtió en súbdita de los romanos". ${ }^{5}$

La nueva provincia, que quedó bajo el control directo del emperador y el gobierno de un legatus Augusti pro praetore, coincidía aproximadamente con el territorio del antiguo reino nabateo, con el añadido de algunas ciudades de la Decápolis (como Gerasa y Philadelphia-Ammán). La capital -como ya se ha dicho- se situó en Bosra, donde estuvo el campamento de la única legión estacionada en la provincia hasta la época del gobierno de Diocleciano: la III Cyrenaica. Pero, aunque perdiera el estatus de capital, parece que no disminuyó la importancia de Petra, como confirman -entre otros aspectos- los títulos que recibió por parte de los emperadores: en el 114 Trajano le otorgó el de metropolis (como atestigua una inscripción griega encontrada en el llamado cardo), ${ }^{6}$ en el $131-\mathrm{y}$, según algunos, durante la visita de Adriano- recibió el título de Hadriana Petra metropolis, y el de colonia bajo Heliogábalo (como prueban las monedas). ${ }^{7}$

Ya en el siglo III, está probado el de metrocolonia. ${ }^{8}$ Todavía en el siglo VI seguían en uso todos estos magníficos honores: Augustocolonia, Antoniniana, Metrocolonia, Hadriana, Petra Metropolis, tal y como aparecen mencionados en uno de los papiros encontrados en la iglesia de los Mosaicos de Petra, reflejando la romanización de la ciudad, al menos en términos administrativos y de estatus. ${ }^{9}$ Indudablemente, un factor importante en la construcción de identidades personales y comunales es precisamente este de los distintos estatutos concedidos. En este sentido, Petra gozó desde el principio de una atención especial por parte de Roma, más destacable incluso que la de la propia Bosra; quizá por el estrecho contacto mantenido por la ciudad antes de la creación de la provincia de Arabia lo que influyó en su consideración por parte de los emperadores.

Al hablar sobre los cambios experimentados en la antigua capital nabatea tras la anexión, se deben destacar las novedades arquitectónicas, que constituyen sin duda el legado romano más visible en las distintas ciudades de la parte oriental del imperio. Ciertamente, las largas líneas de las calles columnadas que se cruzan entre sí, los arcos triunfales, templos, teatros, ninfeos y baños, imponen su imagen en el espacio urbano homogeneizándolo, transformándolo en algo reconocible a simple vista, identificable con la grandeza y el poder de Roma. Como cualquier otra ciudad romana oriental, Petra no fue ajena a este fenómeno pues, inmediatamente después de la anexión y en un breve espacio de tiempo, a lo largo del siglo II d.C., se construyeron la calle pavimentada y columnada que atraviesa el centro de la urbe, la puerta monumental en el extremo occidental y las tiendas ubicadas en el confín oriental de dicha calle, unos baños, un ninfeo, un templo dedicado al culto imperial y una exedra igualmente relacionada con la familia imperial antonina; finalmente, cabe mencionar un monumento funerario que queremos destacar y considerar aparte: la tumba del gobernador Sextius Florentinus.

\footnotetext{
D.C. 68.14.6. Otras referencias más tardías sobre la creación de la provincia de Arabia por orden de Trajano, se encuentran en Amiano Marcelino (14.8.13), Festo (14.3), Eutropio (8.3) y Eusebio (2.220).

Tracy 1999, 51-58 (de donde $A E$ 1999, 1703).

Spijkerman 1978, 220-235, 218, 220-21 y 237. Véanse también, al respecto del título de colonia, las inscripciones recogidas por Karz Reid 2005, 128-131 (de donde $A E$ 2005, 1597 y 1598), ambas halladas en el Pequeño Templo.

8 Como atestigua una inscripción encontrada en el témenos del templo nabateo de Qasr al-Bint. Vid. Starcky Bennet 1968, 60 (AE 1968, 527).

$9 \quad$ Koenen 1996, 187.
} 


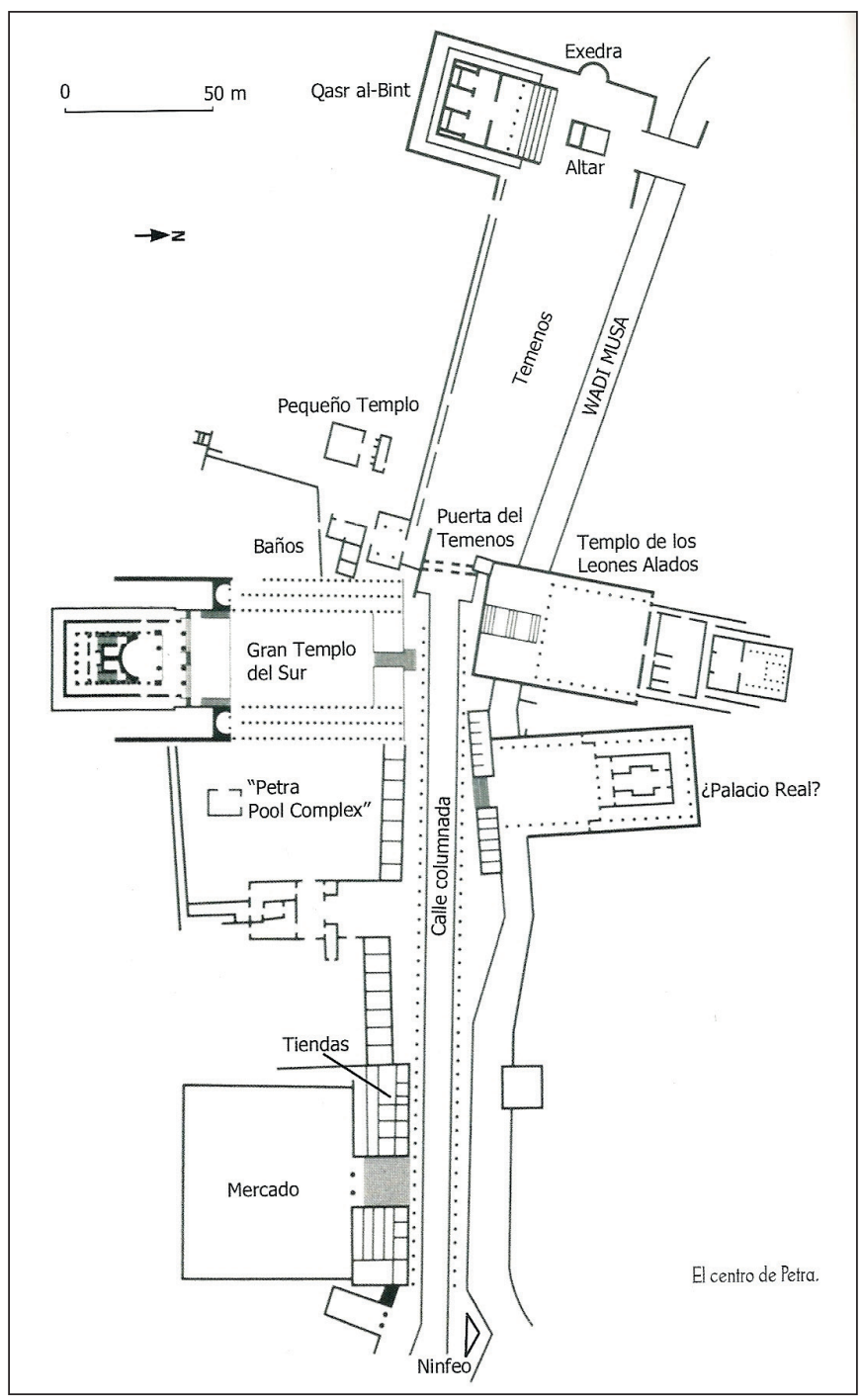

Figura 1. El centro de Petra (Blánquez - Del Río 2010, 96).

Sin embargo, la mayoría de estas nuevas construcciones simplemente otorgaron una imagen renovada al diseño urbanístico nabateo previo porque, en realidad, la calle que forma un eje este-oeste en el centro de la ciudad ya existía; hubo una puerta que separaba la zona cívica del témenos perteneciente al templo nabateo de Qasr al-Bint exactamente en el mismo lugar de la nueva puerta construida en época romana; las termas se situaron junto a unos baños nabateos ya existentes y, finalmente, las tiendas romanas se ubicaron en el mismo emplazamiento de las precedentes tiendas nabateas o, mejor dicho, petrenses. En cuanto al ninfeo, es muy posible que hubiera previamente, en el mismo lugar en que se levantó, un suministro de agua, una fuente nabatea, dado su emplazamiento en la confluencia de dos wadian: el wadi Mataha y el wadi Musa. Dicho diseño urbanístico absolutamente petrense, había sido resultado 
de una gran actividad constructora que siguió una planificación previa y se llevó a cabo fundamentalmente a lo largo del siglo I d.C., bajo el reinado del monarca nabateo Aretas IV (9 a.C.-40 d.C.), el más largo y próspero de toda la historia nabatea.

Además, en Petra fue imposible desarrollar un auténtico diseño urbanístico porque la orografía del terreno lo impedía, y esto marca la diferencia con otras ciudades contemporáneas romano-orientales. Como describen las propias fuentes antiguas, Petra está situada en un valle rodeado de montañas, por cuyo centro discurre el wadi Musa.$^{10}$ En realidad, este centro de la ciudad no es más que un estrecho pasillo que se extiende en dirección este-oeste, rodeado en el norte y en el sur por colinas y cerros que ocupan la mayor parte de la superficie de dicho valle. Es la única zona realmente llana o plana y, dadas sus escasas dimensiones, sólo incluía el curso del wadi y una calle o vía que corría paralela a él. En las laderas de las colinas y cerros más próximas (mirando al wadi y a la calle) se situaron los principales edificios de la ciudad nabatea: templos, mercados, tiendas, etc. Más allá, estaba la zona de viviendas y las necrópolis.

\section{Las transformaciones y renovaciones}

\subsection{La calle Columnada o calle Romana (Fig. 2)}

Era originalmente un camino de arena y grava que después se empedró con pequeños guijarros irregulares procedentes del lecho del wadi Musa. ${ }^{11}$ Bajo el reinado del rey nabateo Aretas IV se construyó en ella un pórtico asociado a unas habitaciones que se consideran tiendas. Es, en realidad, la única calle de la ciudad que merece realmente ese nombre y se extiende -como ya se ha dicho- a lo largo de la única zona completamente llana o plana. Aunque se haya perdido gran parte de su trazado original, parece evidente que éste comenzaba en la principal entrada de la ciudad (la del este, a través del desfiladero conocido como Siq) y llevaba hasta un templo, Qasr alBint; de ahí que algunos ${ }^{12}$ la consideren una vía procesional, un rasgo típico nabateo que se repite en otros enclaves del reino como Sela y Qanawat e incluso en ciudades que estuvieron bajo la órbita nabatea, como Gerasa y Damasco.

La nueva construcción tuvo lugar muy poco después de la anexión, bajo el reinado del emperador Trajano; la vía se pavimentó con losas de caliza y se bordeó con columnas y un pórtico en el lado sur techado con vigas de madera, dando así lugar a la aparición de una típica calle columnada romana, pero sin otras que la cruzaran. Tradicionalmente recibe el nombre de "cardo de Petra", aunque sería más correcto otorgarle la denominación de "decumano" dada su orientación este-oeste.

\footnotetext{
10 Str. 16.4.21.

11 Ha sido excavada únicamente en algunas pequeñas zonas: en la década de los cincuenta del pasado siglo por D. Kirkbride, en la de los sesenta por P. Parr y en la de los noventa por Z. Fiema.

12 Como, entre otros, Segal 1997, 44, y Ball 2000, 256.
} 


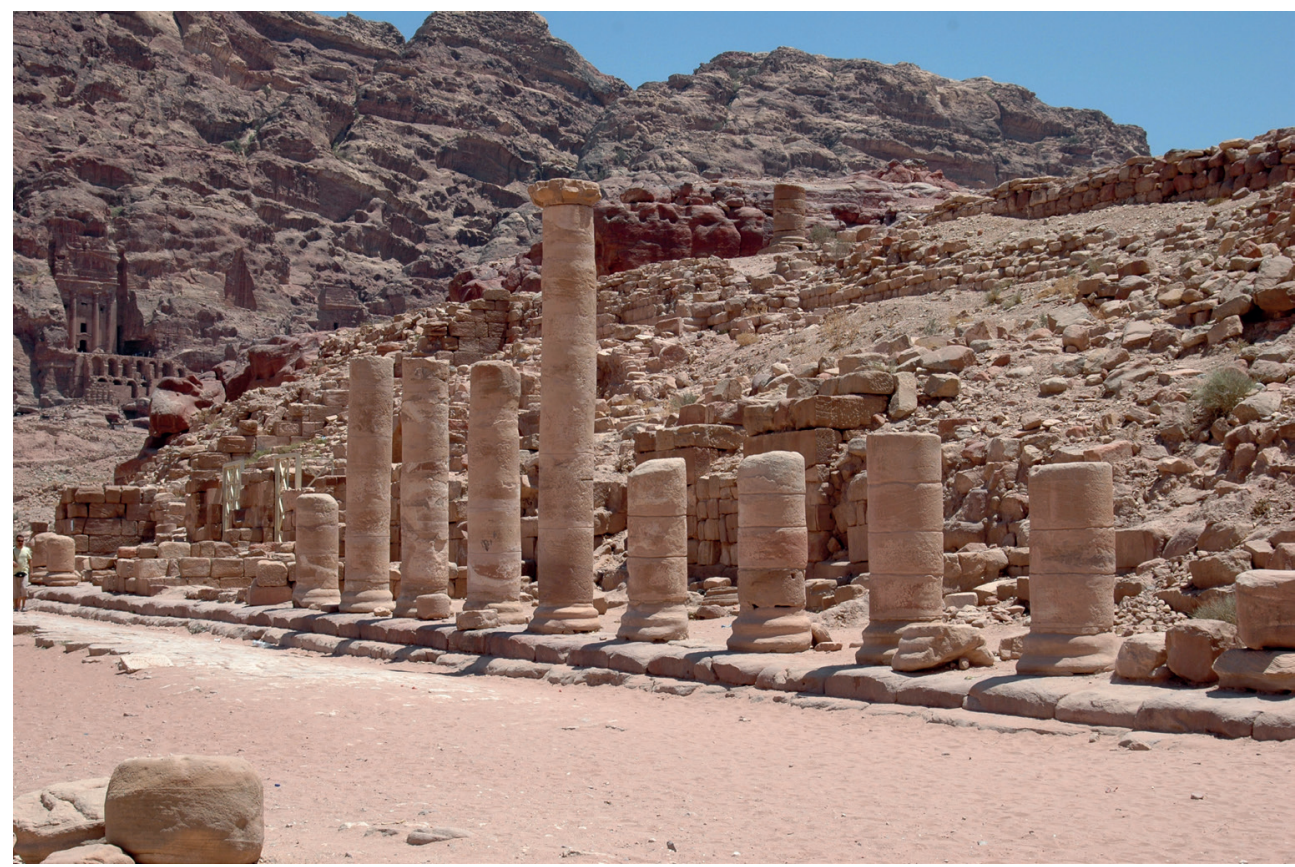

Figura 2. Calle Columnada o calle Romana (C. Blánquez).

El tramo visible hoy día de la calle comienza en el extremo oriental, a la altura de la confluencia de los wadian al-Mataha y Musa (precisamente donde los romanos construyeron el ninfeo) y finaliza en la puerta del témenos del templo nabateo de Qasr al-Bint: unos doscientos cuarenta metros en total. Al sur de la vía (al norte está el wadi Musa), detrás del pórtico, se ubican sucesivamente los llamados Mercados Alto y Medio, un Paradeisos y el Gran Templo del Sur; además, hay dos grandes escalinatas que dan acceso a este templo y al Mercado Alto, así como unas tiendas romanas. Al norte de la calle se conservan los restos de al menos cuatro puentes que cruzaban el wadi Musa y comunicaban con las laderas de las colinas situadas al norte de la ciudad. Sólo se conservan in situ diecinueve bases de columnas de un total de setenta y dos (treinta y seis a cada lado de la calle) y sólo hay suficientes tambores de columnas como para reconstruir nueve (los demás se reutilizaron en épocas posteriores). Las columnas no tienen ménsulas o pedestales a diferencia de otras calles columnadas de ciudades orientales ${ }^{13}$ y el espacio que las separa va disminuyendo en dirección al oeste, quizás debido al deseo de crear un efecto de perspectiva en dirección hacia la puerta del témenos, aunque también puede que fuera algo accidental, debido a una mala ejecución.

Las calles columnadas constituyen el rasgo arquitectónico romano más típico, siempre presente en las ciudades orientales, y les otorgan un aspecto característico inconfundible, como en el caso de Apamea, Palmira, Bosra, Gerasa, etc. Petra no fue una excepción, Roma embelleció el trazado de la vía procesional ya existente pero,

13 Como la calle principal de Palmira, en la actual Siria. 
además de la transformación estética, la calle jugaba un papel destacado en la vida económica y social de la ciudad pues, al ser su arteria principal, a ella estaban asociados establecimientos comerciales, templos, mercados, baños, tabernas, etc. Esta avenida constituyó, pues, el mayor espacio público de Petra, símbolo de su nuevo estatus como uno de los más importantes centros urbanos de Oriente. Conservó su función de paseo y vía de comunicación dentro del corazón de la ciudad, estrechamente relacionado tanto con las actividades comerciales de Petra como con las ceremoniales y religiosas. Es difícil atribuirle una función nueva (respecto a la calle nabatea previa), aunque lo cierto es que ahora sólo era usada por peatones, como confirma la ausencia de huellas de carros que parece que sí estaban presentes en la anterior calle nabatea.

El terremoto del año 363 le causó daños importantes, especialmente graves en el área de confluencia de los wadian, que no fueron completamente reparados. Algunos de los tambores de columnas caídas y también bloques labrados se reutilizaron en la construcción de nuevas tiendas en la etapa bizantina, que invadían parte del espacio de la antigua calle romana y que experimentaban periódicamente los efectos de las torrenteras y de las crecidas de los wadian, en lo que parece un testimonio claro del abandono de las estrictas normas municipales que indicaban las medidas a adoptar, precisamente para evitar los posibles daños causados por las lluvias torrenciales.

\subsection{Las tiendas romanas de dos pisos (Fig. 3)}

Se construyeron sobre unas habitaciones de forma más o menos cuadrada que existían ya en la etapa nabatea y que contaban con un pórtico delante; aunque la función de éstas últimas no es segura, es muy probable que fueran igualmente tiendas. ${ }^{14}$ Tras la anexión, las habitaciones nabateas se ampliaron hacia el norte adoptando ahora forma rectangular y se creó un nuevo pórtico con columnas, separado de la calle por dos escalones. La función de estos nuevos recintos no ofrece dudas gracias a los objetos encontrados, como jarras de almacenaje y numerosas monedas.

Se han excavado y restaurado cinco establecimientos ${ }^{15}$ situados en el extremo oriental de la calle, junto a la gran escalinata que da acceso al Mercado Alto o Superior, pero se calcula que existieron más de treinta. Uno de los espacios excavados $\left(n^{\circ} 28\right)$ se considera una taberna pues se han hallado zócalos agrupados en pares en los que se ajustaban hasta nueve lechos con patas de hierro, donde se reclinarían los clientes para comer y beber. Otro $\left(\mathrm{n}^{\circ} 29\right)$, alojaba un tesorillo de más de cien monedas y la puerta de entrada era notoriamente más estrecha $(0,89 \mathrm{~m}$ frente a $1,60 \mathrm{~m}$ o más) quizá para garantizar una mejor seguridad del recinto. ${ }^{16}$

\footnotetext{
14 No se han sacado a la luz, aunque su existencia está constatada gracias a las excavaciones de los establecimientos comerciales romanos efectuadas dentro del Roman Street Petra Project, dirigido por Z. Fiema.

A fines de la década de los noventa del siglo XX.

16 Vid. Fiema 1998, 403-406 y 412-15; Kanellopoulos 2001, 16-17.
} 


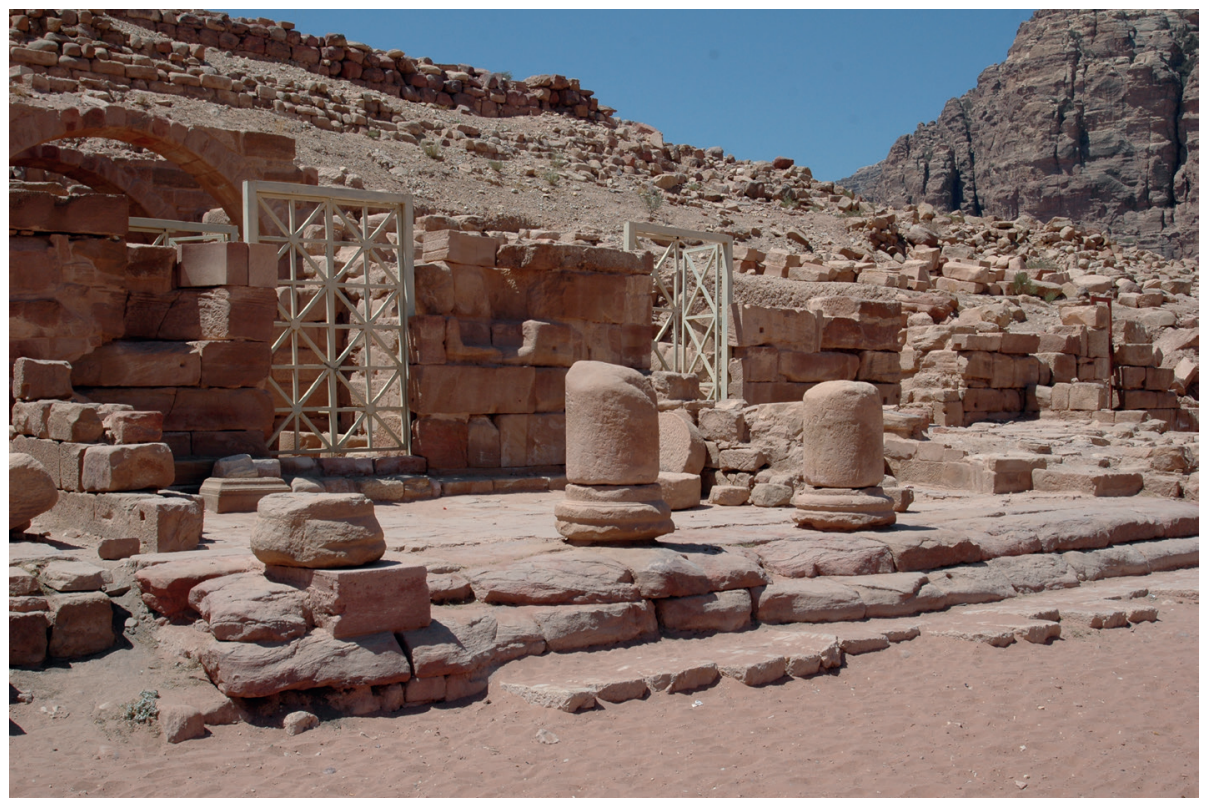

Figura 3. Tiendas romanas (C. Blánquez).

\subsection{La Puerta del témenos (Fig. 4)}

La Puerta del témenos del templo nabateo Qasr al-Bint parece un arco triunfal romano con tres vanos (el central de mayor tamaño), y así se ha considerado y nombrado durante mucho tiempo. Pero, en realidad, es un arco ubicado en un lugar prominente de la ciudad, al final occidental de la calle Columnada, y sería mejor considerarlo simplemente conmemorativo puesto que no hubo guerra de conquista previa a la anexión de Nabatea. Las dudas persisten pues no se ha hallado ninguna inscripción que contribuya a establecer claramente su papel. Además, se levantó sobre una antigua puerta nabatea flanqueada por torres, que separaba la parte cívica de la ciudad de la sacra, es decir, del témenos del templo nabateo llamado Qasr al-Bint y siguió cumpliendo esa misma misión. Por eso no está perfectamente alineada con la calle Columnada, sino con el témenos del templo nabateo.

Se construyó con piedra arenisca rosada y las pilastras que enmarcan la puerta central están decoradas con paneles cuadrados que albergan relieves con motivos florales y bustos con la cara destruida que quizá representan dioses. En su lado oriental se ubicaron filas de columnas enmarcando los tres vanos. Cronológicamente es un poco posterior a la pavimentación de la calle columnada, que tuvo que ser reparada al levantar la puerta, lo que da una fecha en torno a mediados del siglo II. ${ }^{17}$

Es posible que, frente a la escalinata monumental que da acceso al llamado Mercado Alto (cuya construcción pudo coincidir con la de la calle columnada), se levantara otro arco triunfal o conmemorativo al que pudo pertenecer la gran inscripción escrita en griego encontrada en la zona, donde se lee: Petra metropolis. Como men-

17 Vid. Wright 1961; Zayadine 1981, 353. 
ciona a Claudio Severo, el primer gobernador de la provincia de Arabia, tanto la concesión del título de metrópolis como la construcción del Arco se asocian con Trajano y tuvieron lugar muy poco tiempo después de la anexión (en torno al año 117). ${ }^{18}$

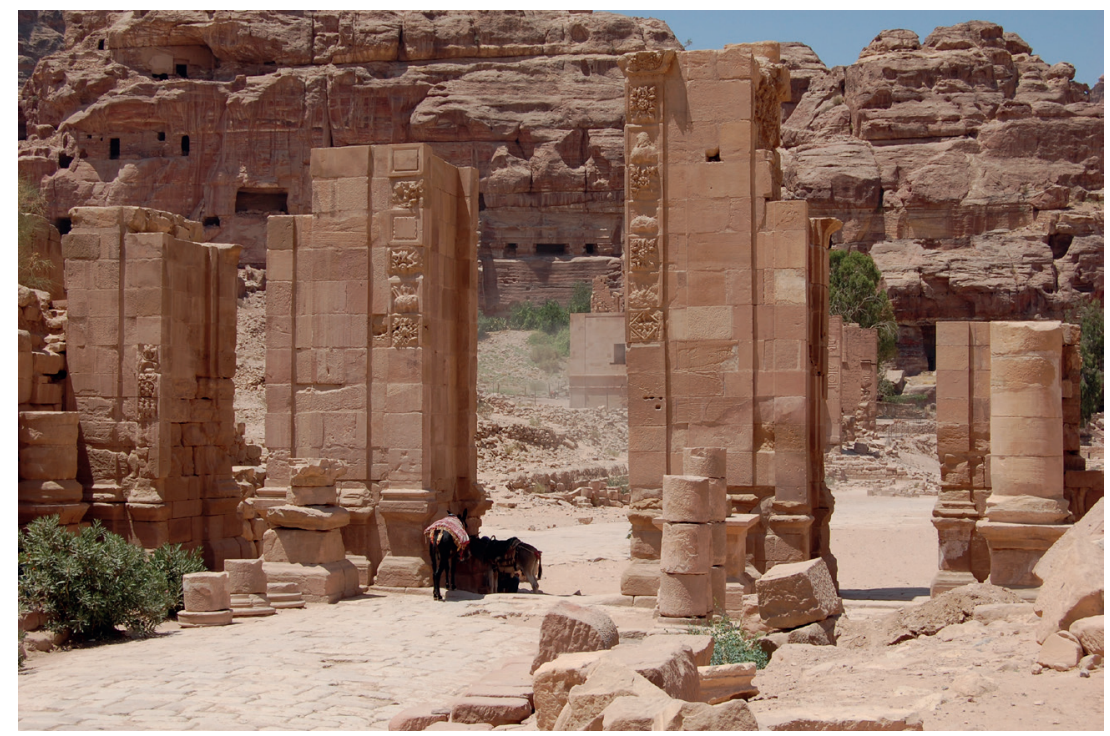

Figura 4. Puerta del témenos (C. Blánquez).

\subsection{Las termas romano-bizantinas}

Salieron a la luz a comienzos del siglo XXI, en las excavaciones realizadas en el área contigua al Gran Templo del Sur ${ }^{19}$ y están ubicadas al oeste del recinto religioso. Se construyeron a comienzos del siglo II d.C., coincidiendo con la anexión romana y estuvieron en uso hasta el 551. Dos caldaria, tepidarium, laconium, frigidarium, apodyterium, praefurnium y una posible palestra integran el conjunto; en realidad, ofrecen todos los rasgos propios de un balneum, dado su pequeño tamaño $(30$ x 30 $\mathrm{m})$. Se trata de un edificio típicamente romano, a añadir en el grupo de los construidos en la ciudad en el siglo II d.C., pero no constituyó realmente una novedad en Petra, pues se conoce la existencia de otros baños (dos cámaras subterráneas) anteriores, de época nabatea, que no han sido excavados. ${ }^{20}$

18 Bowersock 1983, 84-85, n. 28 (cf. $A E$ 1982, 904); Tracy 1999, 51-58; Fiema 2008, 162-163.

19 Durante las campañas de los años 2005-6, bajo la dirección de M. S. Joukowsky. Vid. Joukowsky 2007, 154158 .

20 Únicamente se han limpiado dos cámaras subterráneas comunicadas, una circular y otra cuadrada, ambas con el techo en forma de cúpula con una apertura en el centro, a las que se desciende por una escalera. En su construcción se empleó piedra arenisca dispuesta en sillares. Las paredes de la cámara circular (que tiene unos $5 \mathrm{~m}$ de diámetro) están muy decoradas: medias columnas con capiteles florales enmarcando nichos, una banda con rosetas, así como otros motivos; todo estaba cubierto por estuco pintado de vivos colores (rojo, azul). La cámara cuadrada es algo más pequeña, no ha sido limpiada hasta llegar al suelo como la otra y también tiene restos de estuco. 


\subsection{El Ninfeo}

Por lo que respecta al Ninfeo, la fuente pública ornamentada cuya presencia era ineludible en cualquier ciudad romana que se preciara, los escasísimos restos que quedan de él y el hecho de que no se haya excavado, impiden hacer ningún tipo de comentario. Hoy día únicamente es visible parte de la base de la estructura, con forma semicircular, bajo la sombra de un espléndido árbol de pistacho (que ha sobrevivido unos 400 años).

Está en el extremo oriental de la calle columnada, en la confluencia del wadi Musa y el wadi Mataha, precisamente en el mismo lugar donde quizás hubo una fuente pública nabatea. Los ninfeos eran en las ciudades romanas un símbolo de lujo, pero sabemos que la Petra nabatea ya contaba con cascadas, fuentes y paradeisos y este ninfeo fue un monumento más -en este caso construido en la etapa romanarelacionado con el agua, ese inapreciable bien en una ciudad situada en medio del desierto.

\section{Los cambios}

Los restos de todos estos edificios romanos (menos los baños) eran perfectamente visibles, aunque han sido las tareas de limpieza y excavaciones parciales las que han permitido datarlos con exactitud en la etapa inmediatamente posterior a la anexión: el siglo II d.C. Se pueden interpretar como elementos de un gran proyecto que incluía la renovación de la ciudad de acuerdo con un plan urbanístico que, en realidad y en su mayor parte, se superpuso y adaptó a estructuras nabateas ya existentes. Aunque, desde luego, significan la nueva realidad política y el nuevo prestigio de ser una metrópolis romana.

Cabe mencionar, además, que otros edificios ya existentes en la época nabatea experimentaron cambios tras la anexión, cambios que, en ocasiones, afectaron a su propia función. Vamos a hablar de tres casos: el Petra Garden Pool-Complex, el Teatro Principal y el Gran Templo del Sur.

\subsection{El Petra Garden Pool-Complex}

Este complejo ${ }^{21}$ está situado al sur de la calle columnada, seis metros por encima, junto al Gran Templo del Sur (con el que mantiene una conexión), en el espacio que tradicionalmente se denominaba Mercado Bajo, ${ }^{22}$ ocupando una gran superficie $(65 \mathrm{x}$ $85 \mathrm{~m}$ ). Se trata de una piscina monumental con una isla ubicada en su centro donde se levantó un pabellón, todo ello acompañado por un complejo sistema hidráulico que regaba una gran terraza de tierra situada debajo, cubierta de plantas; en definitiva, un paradeisos (tal y como lo califica la arqueóloga que lo excavó). El complejo fue construido al mismo tiempo que el mencionado Gran templo, a fines del siglo I a.C., durante el reinado del rey nabateo Aretas IV, y parece que el acceso estaba limitado. Tras la anexión romana, cambió su función transformándose en un jardín público y

\footnotetext{
21 Se comenzó a sacar a la luz en el año 1998 y, con algunos períodos de inactividad, continúa todavía hoy en proceso de excavación dirigida por Leigh-Ann Bedal (Pennsylvania State University). Vid. Bedal 2003.

22 De acuerdo con el mapa de la ciudad y la interpretación de W. von Bachmann en 1921.
} 
se añadió un puente abovedado para acceder fácilmente a la isla y al pabellón (al que antes sólo se accedía en barca o nadando, como en Iraq al-Amir y en el Herodium). ${ }^{23}$

El terremoto del año 363 destruyó la estructura, el pabellón y el puente, aunque es posible que el jardín hubiera perdido ya su finalidad de espacio de recreo tiempo atrás.

\subsection{Gran Templo del Sur (Fig. 5)}

Otro de los monumentos nabateos que experimentó cambios en la etapa romana es el llamado Gran Templo del Sur, que actualmente es uno de los edificios más emblemáticos de Petra debido a su tamaño y a su excelente estado de conservación, pues gran parte de los muros se ha preservado gracias a que quedaron enterrados bajo toneladas de arena al derrumbarse la ladera de la colina donde está situado, durante el ya citado terremoto del año 363; además, las labores de restauración realizadas en él, han contribuido a conseguir un aspecto imponente del templo y permiten pasear por el recinto. ${ }^{24} \mathrm{El}$ nombre que recibe alude a su ubicación, al sur del curso del wadi Musa que divide en dos el centro de la ciudad, y al sur igualmente de la calle columnada cuyo trazado es paralelo al del wadi. Y alude también a su enorme tamaño, que queda ejemplificado en el hecho de que el diámetro de las columnas supera el metro y medio y que la superficie excavada mida unos $11.000 \mathrm{~m}^{2}$. La cronología del edificio ha sido difícil de establecer. Finalmente, Joukowsky ha establecido catorce fases de construcción y ocupación, así como una previa de preparación, que transcurren desde inicios del siglo I a.C. hasta la época moderna e incluyen etapas nabatea, romana, bizantina, islámica (y actual) con periodos de abandono. ${ }^{25}$

Una escalera monumental que parte de la calle Columnada, lleva hasta un enorme patio pavimentado con losas hexagonales: el primer témenos, que conserva el pavimento original. Lo flanquean pórticos columnados en los lados este y oeste, que acaban en sendas exedras, provistas de nichos para colocar estatuas. Desde este nivel, mediante escaleras laterales, se accedía a otro patio superior (un segundo témenos) igualmente pavimentado, en el que se encuentra el templo, períptero, tetrástilo in antis, de enormes dimensiones ( 42 × $35 \mathrm{~m}$ de lado y más de $19 \mathrm{~m}$ de alto) y elevado sobre un podio.

Uno de los rasgos más curiosos de este edificio son los capiteles con cabezas de elefante que coronaban las columnas del patio inferior. También es destacable que se han conservado en algunas zonas los fragmentos de estuco que cubrían las paredes y columnas, decorados con colores rojo, azul, verde y blanco, que debían otorgar al conjunto un aspecto singular (y muy diferente del que ofrece hoy día, con los bloques de piedra sin cubrir).

En el siglo I d.C. (fase V) se construyó en su interior (en la cella) un teatro con gradas en forma de hemiciclo, o más bien un odeón, si se consideran sus pequeñas dimensiones (se cree que podría albergar unas 600 personas en sus trece filas de asientos). El hallazgo del teatro ha planteado dudas sobre la función original del edificio: ¿era realmente un templo o se trataba en realidad de un complejo palacial, de

\footnotetext{
3 Bedal 2003, 72-76.

24 Fue excavado por M. S. Joukowsky (Brown University) en sucesivas campañas desarrolladas entre los años 1993 y 2006.

25 Joukowsky 2007, 228-231.
} 
un lugar destinado a las audiencias reales y concebido también como salón de banquetes? Esta transformación tuvo lugar a fines del siglo I, durante el reinado del último rey nabateo, Rabel II, pero no se completó hasta después de la anexión romana. En realidad, la función y el propósito del Gran Templo siguen siendo controvertidos. Es difícil determinar su verdadero carácter, aunque pudiera tratarse de una estructura religiosa que también tuvo una función política. ${ }^{26}$

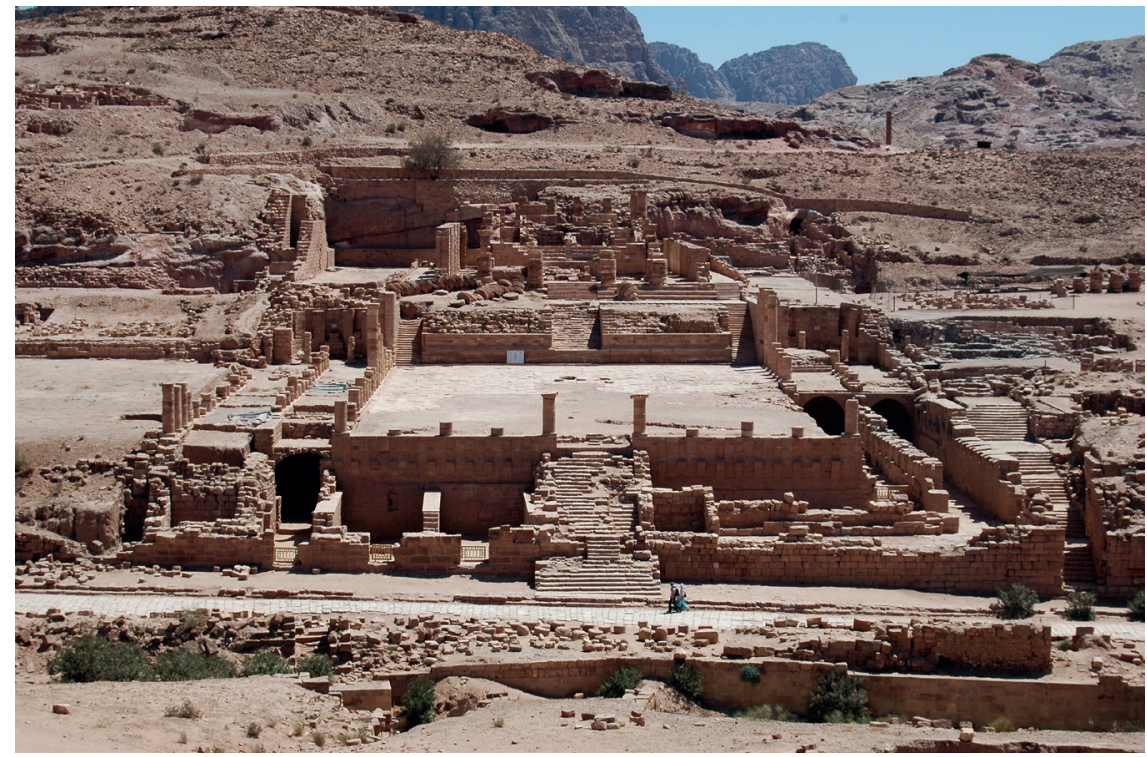

Figura 5. Gran Templo del Sur (C. Blánquez).

Aunque hubo reocupación posterior (estructuras domésticas), la destrucción causada por el terremoto del año 363, o incluso antes, a fines del siglo II d.C., puede considerarse el punto final de la fase $\mathrm{V}$ de este edificio. ${ }^{27}$

\subsection{EI Teatro Principal (Fig. 6)}

El Teatro Principal nabateo (hubo otro, más pequeño) se labró completamente en la roca de la ladera del gran cerro Attuf (menos la escena, que se construyó con bloques de piedra arenisca recubierta con mármol y estuco). ${ }^{28}$ Fue excavado por $\mathrm{Ph}$. Hammond durante la década de 1960, confirmando que se trataba de una obra nabatea, aunque experimentó modificaciones en la etapa romana. ${ }^{29}$ Está situado enfrente de la montaña al-Khubthah y frente al camino que lleva desde el Siq hacia el centro de la ciudad y se elaboró bajo el reinado de Aretas IV (9 a.C.-40 d.C.), avanzado el siglo I d.C.

26 La propia arqueóloga que excavó este grandioso monumento no ha elaborado una respuesta definida sobre lo que ella misma califica como: The Great Debate. Vid. Joukowsky 2007, 350-355 y 400-405; Joukowsky Basile 2001, 43-58.

27 Joukowsky 2007, 20.

28 Es el único teatro de todo el mundo romano enteramente cortado en la roca, al estilo nabateo.

29 En contra de la opinión mantenida hasta entonces que lo consideraba obra romana. Hammond 1965, 62. 
El diámetro aproximado de la cávea semicircular es de unos $100 \mathrm{~m}$ y su altura de unos $24 \mathrm{~m}$; contaba con 45 filas de asientos (una capacidad de casi 4000 personas sentadas); los asientos están divididos horizontalmente en tres secciones (moeniana): 11 asientos, 34 y 10, así como divididos verticalmente en 6 secciones (cunei) por hasta 5 filas de escaleras que no llegan hasta la parte más superior. Sin insistir con más detalles, lo cierto es que sigue el modelo de Vitrubio y es un teatro típicamente romano, aunque en el método de construcción algunos rasgos son claramente nabateos (sistema hidráulico, decoración floral de capiteles nabateos, técnica de albañilería, etc.). Por encima de la última fila de asientos se distingue la pared vertical, alisada y cortada del cerro, y se perciben claramente tumbas nabateas. Este es probablemente el rasgo más curioso de este teatro nabateo: la unión de espacio funerario y cívico. Su uso en la etapa romana se desconoce, como se desconoce igualmente su función en la etapa nabatea.

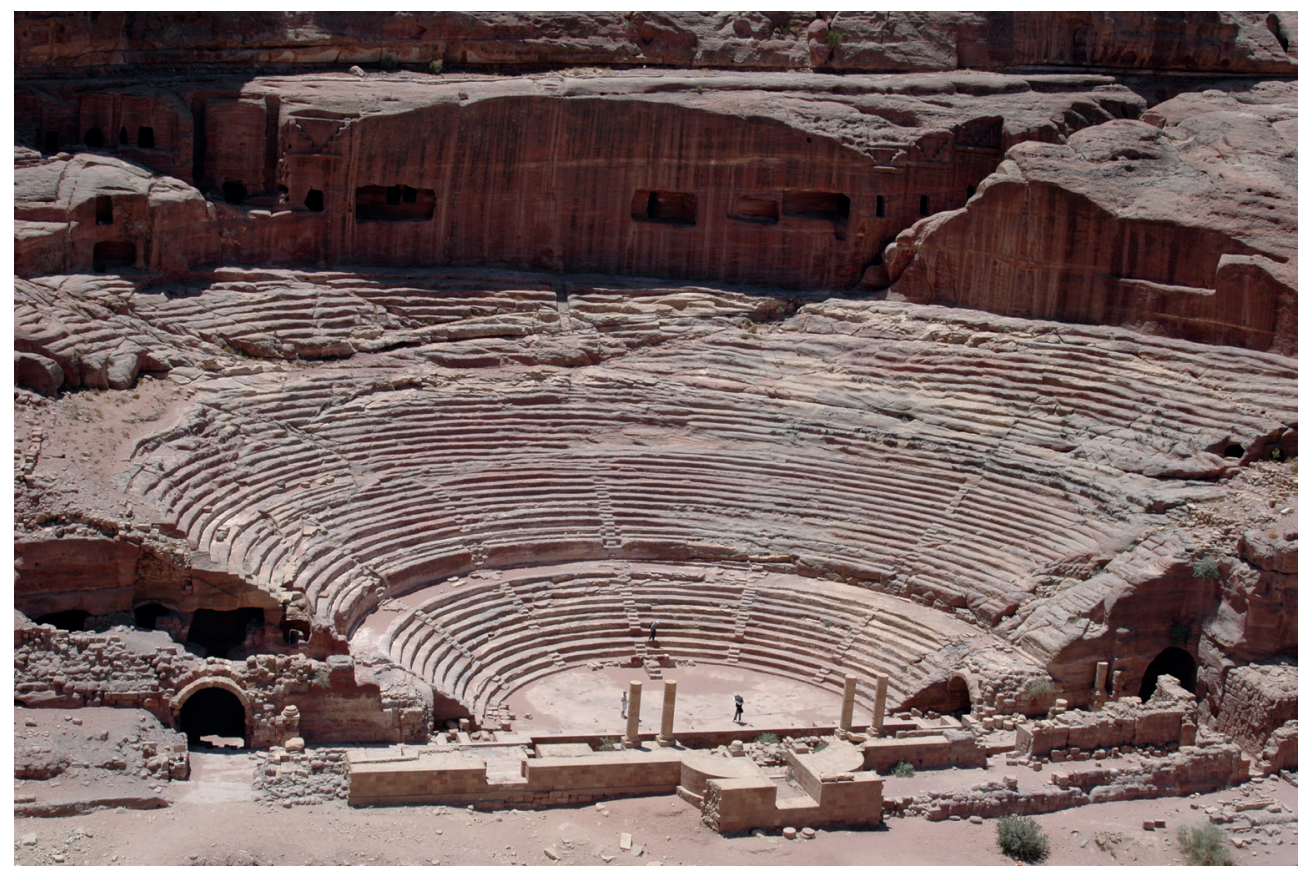

Figura 6. El Teatro Principal (C. Blánquez).

El terremoto del 363 lo afectó gravemente y las torrenteras que, durante siglos, han avanzado por el camino hacia el centro de la ciudad acabaron con la parte de la escena, que ha sido reconstruida en época moderna.

\section{Las novedades. Los hallazgos más recientes}

Otros descubrimientos más recientes, que completan el paisaje urbanístico de la Petra romana son los del Pequeño Templo y la exedra del témenos de Qasr al-Bint. 


\section{1. "Pequeño Templo" (Fig. 7)}

$\mathrm{Su}$ hallazgo ${ }^{30}$ constituyó un hito en las novedades urbanísticas de época romana. Está ubicado en la parte sur de la ciudad, por encima del témenos del templo nabateo Qasr al-Bint, es decir, en un lugar prominente y junto a un recinto sagrado para los petrenses nabateos. Aunque su estado de conservación es muy pobre, los restos sacados a la luz (la escalera de acceso y los cimientos del edificio) han sido suficientes para determinar que se trata de un templo cuadrado, hexástilo y ubicado sobre un podio. En su construcción, además de la piedra caliza local, se empleó abundante mármol importado de las islas del mar de Mármara. Gracias a una inscripción incompleta en una placa de mármol que menciona al emperador Trajano, se fecha inmediatamente después de la anexión del reino nabateo, a comienzos del siglo II d.C. ${ }^{31}$ Probablemente el terremoto del 363 causó su destrucción, aunque parte de ella parece intencionada y puede relacionarse con una reacción antipagana.

El aspecto más destacable de este templo romano es que estaba consagrado al culto imperial provincial..$^{32}$ Es imposible saber si su construcción fue resultado de una iniciativa romana, petrense, o petrense siguiendo la voluntad romana. Indudablemente, un templo consagrado al culto imperial es un símbolo de la dominación romana, pero igualmente parece oportuno destacar que la participación en el culto imperial en las ciudades orientales se convirtió en un importante símbolo de la cooperación provincial, deseosa de mantener buenas relaciones con Roma y de aumentar o mejorar el desarrollo de la ciudad. Si fue o no así en el caso de Petra, es imposible afirmarlo con seguridad.

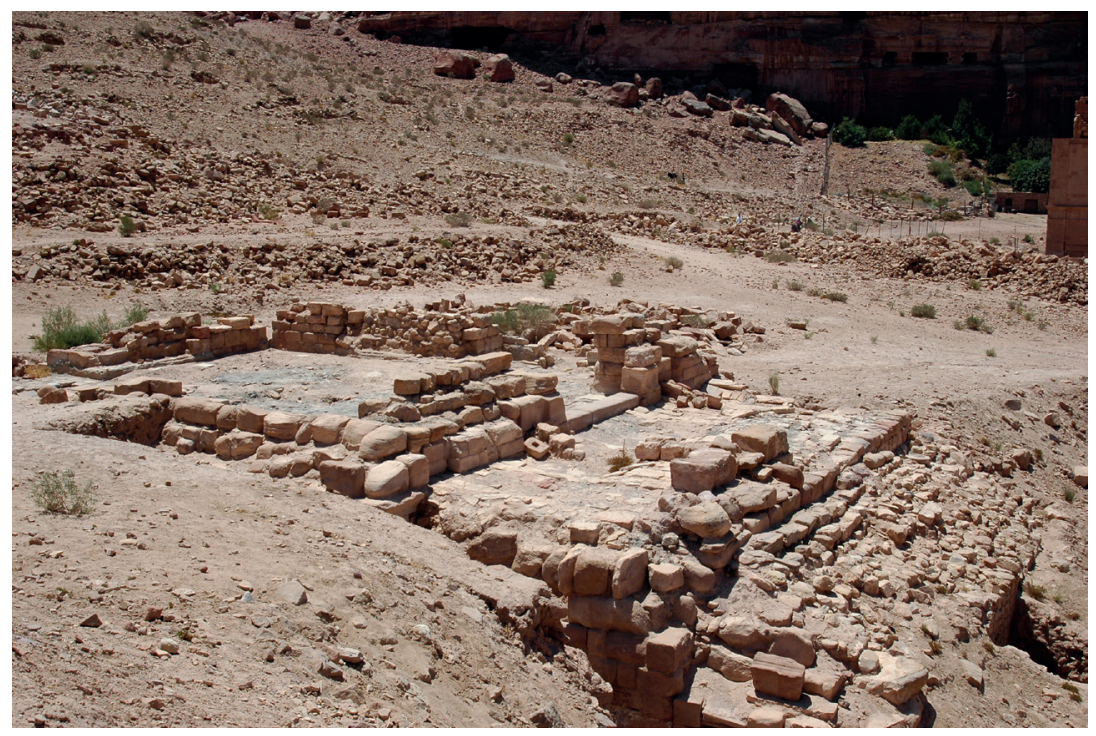

Figura 7. El "Pequeño Templo" (C. Blánquez).

30 Se excavó en sucesivas campañas arqueológicas desarrolladas entre los años 2000 y 2002 dirigidas por S. Karz Reid.

31 Karz Reid 2005, 124-26 (de donde $A E$ 2005, 1596).

32 Karz Reid 2005, 169-188. 


\subsection{Témenos del templo nabateo de Qasr al-Bint (Fig. 8)}

Las excavaciones realizadas en este témenos han sacado a la luz nuevos testimonios de los cambios arquitectónicos que se produjeron en la ciudad tras la anexión. El hallazgo del busto de un personaje romano en las cercanías del témenos (en 1996) propició el comienzo en 2001 de una serie de campañas arqueológicas en esta zona, que continúan en la actualidad. ${ }^{33}$

Indudablemente, el lugar es sacro y se asocia con uno de los principales templos nabateos de Petra. Los restos encontrados hasta el momento muestran una exedra flanqueada por columnas jónicas que enmarcan nichos. Dos inscripciones monumentales en griego, ambas incompletas, han permitido fecharla. Una está dedicada a los emperadores Marco Aurelio y Lucio Vero y les menciona como grandes vencedores de armenios, medos y partos; ${ }^{34}$ y la otra está dedicada a Antistio Advento, gobernador de Arabia durante 167-168 d.C., por un tal Zaidkomos (nombre nabateo). ${ }^{35}$ Entre los restos escultóricos destaca una cabeza colosal (dos veces el tamaño natural) y otros grandes fragmentos (una mano, un pie) de una estatua de Marco Aurelio. También se ha hallado un busto de un personaje masculino barbado identificado con Lucio Elio César, adoptado por Adriano. ${ }^{36}$

Se cree que se trata de una exedra dedicada a honrar a la familia imperial, como la de Shahba-Philippopolis en Siria. ${ }^{37}$ Es por tanto otro testimonio de la propaganda y del culto imperial que se suma al del Pequeño Templo. Por el momento, son los principales símbolos religiosos (y los más elocuentes) del nuevo poder romano en la ciudad.

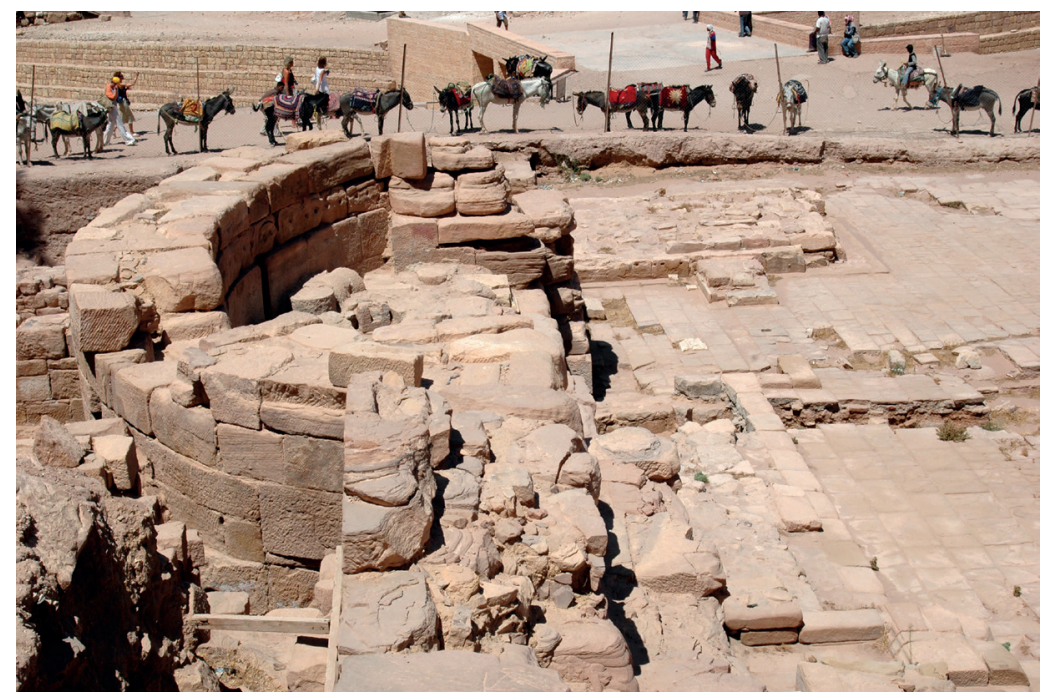

Figura 8. Exedra del témenos del templo nabateo de Qasr al-Bint (C. Blánquez).

\footnotetext{
Llevadas a cabo por un equipo francés dirigido en un principio por Christian Augé.

Zayadine 2002, 209-210 (de donde $A E$ 2002, 1826).

Zayadine 2002, 211 (de donde $A E$ 2002, 1827). Augé 2005, 190.

Identificación realizada por Kreikenbom - Weber 2002, 198.

Zayadine 2002, 213.
} 


\section{La arquitectura funeraria}

\subsection{La tumba del gobernador romano de Arabia Sextius Florentinus (Fig. 9)}

La tumba del gobernador Sextius Florentinus (127-129, reinando Adriano) constituye un caso especial. ${ }^{38} \mathrm{Se}$ trata de una tumba rupestre con la fachada decorada típica de Petra, que mide $10 \times 17 \mathrm{~m}$ y está situada a espaldas del centro de la ciudad pero está excavada en la ladera un pequeño cerro que ocupa un lugar destacado. A diferencia de lo que es usual en las tumbas nabateas de este tipo, incluye un epitafio en latín con el cursus honorum de Sextius y revela que el propio gobernador quiso ser enterrado allí y que su hijo cumplió sus deseos. ${ }^{39}$ La decoración de la fachada incluye una cabeza de Medusa situada dentro de un frontón con la parte superior en forma de arco y la figura de un águila encima; parece que tuvo también urnas pero la erosión impide afirmarlo con seguridad, en cuanto a las columnas tienen capitales nabateos. En el interior hay una única cámara de 8 x 12 con 5 loculi en la pared del fondo enmarcados por columnas y otros tres en la de la derecha; se conservan restos de estuco en las paredes.

Para algunos, la tumba ya existía desde época nabatea y se reutilizó en esta ocasión, para otros se elaboró - siguiendo las costumbres petrenses nabateas- respetando la voluntad de Sextius. En cualquier caso, lo cierto es que tanto la decoración que adorna la fachada como el interior son típicamente nabateos y sólo la inscripción, situada en la fachada en un lugar visible, permite conocer la identidad del enterrado allí: un eminente romano.

Resulta interesante y destacable que, a pesar de la larga pervivencia de la provincia de Arabia y de su sucesora la Palestina Tertia Salutaris, no se produjera ningún cambio en el aspecto de las tumbas de Petra. Las "estrategias de emulación" seguidas por las élites locales no se detectan en las costumbres funerarias.

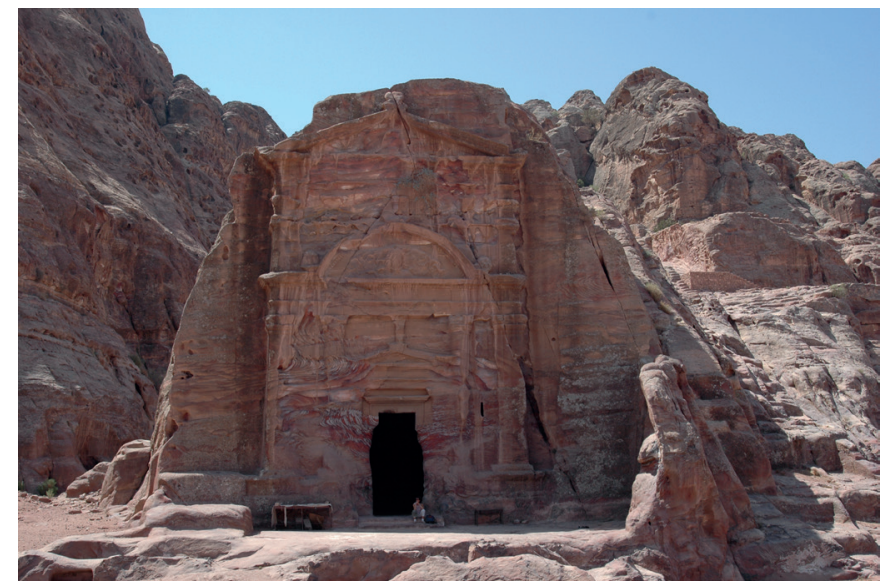

Figura 9. Tumba de Sextius Florentinus (C. Blánquez).

38 Tumba número 763, de acuerdo con la catalogación de Brünnow - Domaszewski II, 1904, 382-384.

39 CIL III 87: T(ito) Aninio L(uci) f(ilio) Pap(iria) Sextio Florentino IIIviro aur(o) arg(ento) flando trib(uno) milit(um) leg(ionis) I Minerviae quaest(ori) prov(inciae) Achaiae trib(uno) pleb(is) leg(ato) leg(ionis) VIIII Hisp(anae) proco(n)sul(i) / pr[ov(inciae)] Narb(onensis) leg(ato) Aug(usti) pr(o) pr(aetore) prov(inciae) Arab(iae) patri piis[sim]o ex testamento ipsius. 
Vamos a proponer a continuación dos ejemplos de tumbas rupestres de Petra que estuvieron en uso durante la etapa que nos ocupa de la provincia de Arabia, para confirmar que no hay ningún rasgo que distinga éstas de las de la etapa nabatea.

\subsection{La tumba $64^{40}$}

Esta tumba está ubicada en la misma explanada donde se sitúa el Khazneh, el monumento más emblemático de toda Petra y se excavó a fines del siglo pasado. Se trata de una tumba rupestre con la fachada decorada, cuya cámara funeraria está ampliamente ocupada pues tiene diez loculi con tumbas de fosa en su interior: cinco en la pared sur, otros tres en la pared este y dos en la norte; también hay tres tumbas de fosa en el suelo de la cámara. Como es usual, las sepulturas habían sido parcialmente saqueadas, pero se encontraron suficientes objetos como para poder datarlas con seguridad, como lucernas que se fecharon entre los siglos II y III d.C., e incluso un enterramiento intacto que contenía el esqueleto de una mujer con un feto entre las piernas junto a otra lucerna y un denario de plata de Septimio Severo. ${ }^{41}$ Gracias a estos ajuares, se sabe que la utilización de la tumba oscila entre los siglos II y IV d.C.

\subsection{LaTumba $550^{42}$}

También conocida como "la del triple Dushara", es una tumba rupestre que se encuentra en Jebel Maiserah, al noroeste de Petra. Fue excavada en 1941 por los primeros arqueólogos que trabajaron en Petra: A. y G. Horsfield..$^{43}$ Aunque el tamaño de la cámara funeraria no es muy grande (alrededor de 4,50 $\mathrm{m}$ de lado) contiene siete tumbas de fosa de las que cinco tienen enterramientos superpuestos; en ellas se descubrieron restos de esqueletos pertenecientes a niños (tres cráneos) y otro de una mujer con un niño (fosa 5). Asimismo, el hallazgo de cal y cenizas con huesos fragmentados se interpretó como testimonio de la práctica de la incineración. En cuanto al período de utilización de la tumba, se sitúa entre los siglos I a.C. y III d.C., según indican dos monedas encontradas: una del rey nabateo Aretas IV (9 a.C.-40 d.C.) y otra del emperador Heliogábalo. ${ }^{44}$

\section{Conclusiones}

El nuevo urbanismo de la ciudad no la transformó significativamente. A diferencia de otras ciudades orientales en las que su diseño original quedó enmascarado con la construcción de nuevas calles y edificios, el trazado del mapa urbanístico de Petra proveniente del siglo I d.C. se mantuvo aunque, utilizando monumentos ya existentes, surgieron todos aquellos que cabe esperar en cualquier urbe romana provincial oriental (calle recta columnada, arcos, teatro, tiendas, ninfeo). La especial orografía de Petra impidió aplicar el tradicional trazado ortogonal y, en cuanto a los

\footnotetext{
Según la catalogación de Brünnow - Domaszewski I 1904, 231.

Zayadine 1981, 341-355.

42 Según la catalogación de Brünnow - Domaszewski 1904, II, 352.

3 Horsfield - Horsfield 1939, 108-110.

44 Delhopital 2010, I, 79.
} 
materiales de construcción: piedra caliza y arenisca, granito, estuco y mármol ya habían sido empleados con anterioridad al dominio romano.

Pero el templo y la exedra consagrados al culto imperial y a la familia del emperador sí suponen una novedad y son especialmente significativos. El culto imperial aparece inmediatamente tras la anexión, con la construcción del Pequeño Templo, y se abunda aún más en esta línea de aceptación y celebración de la nueva realidad con la exedra dedicada a emperadores del siglo II d.C. y a diversos miembros de su familia. Hasta su descubrimiento (y la excavación en la zona de la exedra aún no se considera finalizada) no existía ningún testimonio tan claro y revelador de la nueva situación de Petra, una ciudad provincial favorecida ampliamente por la predilección de los emperadores.

Otro de los factores de cambio y transformación detectados en la arquitectura de la ciudad gracias a la Arqueología, el de la inclusión de un theatron en el Gran templo del Sur de Petra, puede relacionarse con las noticias provenientes del Archivo de Babatha encontrado en una cueva al oeste del Mar Muerto (cerca de en-Gedi). ${ }^{45}$ Como se aprecia en los documentos, una vez que tuvo lugar la anexión de Nabatea, la ley que se aplicaba era la ley romana, la lengua que se utilizaba era el griego y se databan los manuscritos por los años de la provincia (eparcheia) y con los nombres de los cónsules de Roma y del emperador. Se confirma así la frase de Amiano Marcelino que afirmaba sobre Arabia: Hanc provinciae inposito nomine rectoreque adtributo obtemperare legibus nostris Traianus conpulit imperator incolarum tumore saepe contunso cum glorioso marte Mediam urgeret et Parthos. ${ }^{46}$ Una de las menciones más interesantes para el tema que nos ocupa, aparece en un documento fechado en el año 124 d.C. y se refiere a "la Boulé de la metrópolis de Petra", que actúa respecto a las transacciones relativas a la orfandad del hijo de Babatha y cuya acta queda depositada en el "templo de Afrodita de Petra" ${ }^{47}$ El Consejo actuaba presidido por el propio gobernador provincial, que se trasladaba a Petra para administrar justicia, como iría igualmente a otros centros urbanos de la provincia.

Es posible que la inclusión del theatron convirtiera al edificio en un bouleuterion o lugar de reunión donde se discutirían cuestiones relativas a la ciudad; y el gran témenos que lo precede sería por tanto una enorme plaza pública. Si esto es así, esta transformación fue de gran relevancia, pues supuso la alteración del marco de poder y de las formas de referencia que dicho poder utilizaba. Y abundando aún más en los cambios que supuso la introducción de este Consejo en la vida de Petra, cabe pensar que las élites de la sociedad petrense serían quienes ocuparan cargos destacados en la nueva administración provincial, como pudo ser el caso de los miembros de la casa real nabatea de la que no se vuelve a tener noticias. ${ }^{48}$ Ahora las oportunidades eran otras.

45 Su descubrimiento tuvo lugar en 1960 y la cueva fue excavada por Y. Yadin. Este archivo familiar, escondido durante la revuelta judía del Bar Kokhba del 132 d.C., contiene documentos que abarcan los años finales del reinado del último rey nabateo Rabel II y las primeras décadas de existencia de la provincia romana de Arabia. Se refieren principalmente a las acciones legales que Babatha tuvo que emprender para defender los intereses del hijo que tuvo con su primer marido ya fallecido, frente a las demandas de otra esposa de su segundo marido también fallecido.

46 Amm.Marc. 14.8.13.

47 Yadin 1989, 12.

48 Gracias precisamente al Archivo de Babatha se sabe, además, que el último gobernante de Nabatea, Rabel II, tenía un hijo, Obodas, considerado el futuro heredero. Vid. Yadin 1962, 239-240. 
Por otro lado, la aparición y extensión de nuevas costumbres desarrolladas por las élites locales -a imitación de las provinciales romanas- no queda confirmada en el mundo funerario, pues ni las prácticas mortuorias ni las tumbas experimentan cambio alguno: no hay testimonios de "prácticas de emulación" en este ámbito. Por el contrario, el caso de la tumba del gobernador romano Sextius Florentinus es paradigmático y su deseo de ser enterrado en Petra se llevó a cabo en un monumento funerario característico petrense: una tumba de cámara excavada en la roca con la fachada decorada.

Evidentemente, el proceso para conocer los cambios y la formación de la provincia de Arabia apenas ha empezado a mostrarse, pero cabe esperar que nuevas excavaciones arqueológicas saquen a la luz restos cuya interpretación sea reveladora o bien más textos que nos proporcionen información sustancial para conocer esta etapa de la existencia de la ciudad de Petra, ya que se calcula que alrededor del $90 \%$ de sus restos permanecen aún enterrados bajo la arena.

\section{Referencias bibliográficas}

Augé, Ch. (2005): "Nouvelles recherches autour du Qasr al-Bint à Pétra (Jordanie)", Revue Archeologique. Nouvelle Série 1, 186-192.

Augé, Ch. - Renél, F. - Borel, L. - March, C. (2002): "New Excavations in the Qasr al-Bint area at Petra", Annual of the Department of Antiquities of Jordan 46, 309313.

Ball, W. (2000): Rome in the East. The Transformation of an Empire, London.

Bedal, L.-A. (2003): The Petra Pool Complex. A Hellenistic Paradeisos in the Nabatean Capital. Results from the Petra "Lower Market" Survey and Excavation, 1998 (=Gorgias Studies in Classical and Late Antiquity 10), New Jersey.

Blánquez, C. - Del Río, A. (2010): Petra. Historia y Arqueología, Madrid.

Bowersock, G. W. (1983): Roman Arabia, London.

Brünnow, R. E. - Domaszewski, A. V. (1904): Die Provincia Arabia, Strassburg, vols. I-II.

Delhopital, N. (2010): Du monde des vivants au monde des morts en Nabatène, entre le II siècle av. J.-C. et le VIe siècle ap. J.-C.: approche archéoanthropologique des tombes de Khirbet edh-Dharih, Pétra (Jordanie) et de Madâ'in Sâlih (Arabie Saoudite), Thèse de Doctorat, Université Bordeaux 1.

Fiema, Z.

(1998): "The Roman Street of the Petra Project-1997: A Preliminary Report", Annual of the Department of Antiquities of Jordan XLII, 395-424.

(2008): "Remarks on the Development and Significance of the Colonnaded Street in Petra, Jordan", [en] P. Ballet - N. Dieudonné-Glad - C. Saliou (eds.), La Rue dans l'antiquité, Rennes, 161-168.

Fiema, Z. et alii (2001): The Petra Church (=ACOR 3), Amman.

Graf, D. (2007): "The Nabataeans under Roman Rule (after AD 106)", [en] K. D. Politis (ed.), The World of the Nabataeans, Volume 2 of the International Conference The World of the Herods and the Nabataeans held at the British Museum, 17-19 April 2001 (=Oriens et Occidens 15), Stuttgart, 173-186. 
Hammond, Ph. C. (1965): The Excavation of the Main Theater at Petra, 1961-1962. Final Report, London.

Horsfield, A. - Horsfield, G. (1939): "Sela-Petra, the Rock of Edom and Nabatene. The Excavations", Quarterly of Department of Antiquities of Palestine 8, 87-115.

Joukowsky, M. S. (2007): Petra Great Temple II. Archaeological contexts of the remains and excavations: Brown University excavations in Jordan at the Petra Great Temple, 1993-2007, Providence, Rhode Island.

Joukowsky, M. S. - Basile, J. (2001): "More Pieces in the Petra Great Temple Puzzle", Bulletin of the American Schools of Oriental Research 324, 43-58 (http:// dx.doi.org/10.2307/1357631).

Kanellopoulos, Ch. (2001): "The Architecture of the Shops and Colonnaded Street in Petra", Bulletin of American Schools of Oriental Research 324, 9-22 (http:// dx.doi.org/10.2307/1357629).

Karz Reid, S. (2005): The Small Temple, New Jersey.

Kirkbride, D. (1960): "A Short Account of the Excavations at Petra in 1953-56", Annual of the Department of Antiquities of Jordan IV-V, 117-122.

Koenen, L. (1996): "The Carbonized Archive from Petra", Journal of Roman Archaeology 9, 177-188 (http://dx.doi.org/10.1017/S104775940001655X).

Kreikenbom, D. - Weber, Th. M. (2002): "Un nouveau portrait d'Aelius Caesar à Pétra", Syria 79, 195-206.

Mckenzie, J. S. (1990): The Architecture of Petra, Oxford.

Parr, P.

(1960): “Excavations at Petra, 1958-59", Palestine Exploration Quarterly 92, 124-136 (http://dx.doi.org/10.1179/peq.1960.92.2.124).

(1965): "The Beginnings of Hellenisation at Petra", [en] Huitième congrès international d'archéologie classique, Paris 1963, Paris, 527-553.

(1990): "Sixty Years of Excavation in Petra: A Critical Assessment", Aram 2, 7-23.

Segal, A. (1997): From Function to Monument : Urban Landscapes of Roman Palestine, Syria and Provincia Arabia (=Oxbow Monograph 66), Oxford.

Spijkerman, A. (1978): The Coins of the Decapolis and Provincia Arabia (=Studii Biblici Franciscani Collectio maior 25), Jerusalem.

Starcky, J. - Bennet, C. M. (1968): “Les Inscriptions du téménos”, Syria 45, 41-66.

Tracy, S. (1999): "The Dedicatory Inscription to Trajan at the Metropolis of Petra", [en] J. Humphrey (ed.), The Roman and Byzantine Near East. Some Recent Archaeological Work 2 (=Journal of Roman Archaeology. Supplementary series 31), Porstmouth, 51-58.

Wright, G. R. H. (1961): "Petra, the Arched Gate, 1959-60", Palestine Exploration Quarterly 93, 124-135 (https://doi.org/10.1179/peq.1961.93.2.124).

Yadin, Y.

(1962): "Expedition D. The Cave of Letters", Israel Exploration Journal 12, 227 257.

(1989): The Documents from the Bar Kohba Period in the Cave of Letters: Greek Papyri, Jerusalem. 
Zayadine, F.

(1981): "Recent Excavations and Restorations of the Department of Antiquities (1979-80)", Annual of the Department of Antiquities of Jordan 25, 341-355.

(1982): "Recent Excavations at Petra (1979-81)", Annual of the Department of Antiquities of Jordan 26, 365-371.

(2002): “L'exédre du téménos du Qasr al-Bint à Pétra", Syria 79, 207-215. 